\title{
Effect of Active Immunization of Pony Mares against Recombinant Porcine Inhibin $\alpha$ Subunit on Ovarian Follicular Development and Plasma Steroids and Gonadotropins
}

\author{
Refaat Ibrahim DERAR ${ }^{1,2)}$, Yoshihisa MAEDA ${ }^{1)}$, M Shafiqul HOQUE ${ }^{1,3)}$, Takeshi OSAWA ${ }^{1)}$, Gen WATANABE ${ }^{4)}$, \\ Kazuyoshi TAYA ${ }^{4)}$ and Yoh-Ichi MIYAKE ${ }^{1) *}$ \\ ${ }^{1)}$ Laboratory of Theriogenology, Department of Veterinary Medicine, Faculty of Agriculture, Iwate University, Morioka 020-8550, \\ ${ }^{2}{ }^{2}$ Department of Theriogenology, Faculty of Veterinary Medicine, Assiut University, Egypt, ${ }^{3)}$ Department of Clinical Veterinary Science, \\ The United Graduate School of Veterinary Sciences, Gifu University, Gifu 501-1193 and ${ }^{4}$ Laboratory of Veterinary Physiology, \\ Department of Veterinary Medicine, Faculty of Agriculture, Tokyo University of Agricultural Technology, Fuchu, Tokyo 183-8509, Japan
}

(Received 1 November 2002/Accepted 3 September 2003)

ABSTRACT. Two pony mares were immunized against recombinant porcine inhibin $\alpha$ subunit three times with 39 day intervals. Clinical findings and endocrinological changes before immunization were taken as the control. The first significant rise in the anti-inhibin titre $(\mathrm{P}<0.05)$ in the circulation was found 27 days after the first injection. Maximum binding activity was reached by the 12 th day after the second booster dose. The number of small, medium and large sized follicles had increased significantly compared to before immunization (11.75 $\pm 4.30,2.75 \pm 0.69$ and $2.51 \pm 0.63$ vs $6.50 \pm 1.43,1.83 \pm 0.44$ and $1.33 \pm 0.38$, respectively), but the ovulation rate remained unchanged after immunization. The average plasma concentration of FSH and estradiol-17 $\beta$ during the estrous cycle increased significantly $(\mathrm{P}<0.05)$ after immunization. These results suggest that immunization against inhibin is a useful tool to increase the number of ovarian follicles during the estrous cycle of pony mares. Moreover, the present study supported the concept that inhibin plays a major role in the control of follicular growth through its inhibitory effect on FSH secretion synergistically with steroid hormones.

KEY wORDS: follicular development, FSH, immunization, inhibin, mare.

The physiological mechanisms responsible for limiting one follicular development and ovulation from multiple follicles during the normal follicular phase in the mare is not yet fully understood. Attempts at inducing multiple ovulation or promoting fertility in the mare with various treatments such as equine chorionic gonadotropin (eCG), equine pituitary extract and $\mathrm{PGF}_{2} \alpha$ have met with limited success $[2,6,10,12,17,20]$. Currently, crude pituitary extracts are the most reliable method for inducing multiple ovulations in the mare and this method usually results in one to four ovulations per cycle [5], but pituitary extracts are not readily available and the regimens required are relatively intensive.

Inhibin is a large glycosylated protein consisting of two subunits linked by disulfide bridges, and specifically inhibits FSH secretion and suppresses the expression of $\mathrm{GnRH}$ receptors in the pituitary gland $[1,7,15,22]$. On the other hand, the production of inhibin is stimulated by FSH thereby forming a tight feedback circuit $[18,19]$. It is argued that ovarian inhibin may be the most important hormone for determining the species-specific number of ovulations in both single and multiple ovulatory species.

In cattle, active immunization against inhibin enhanced ovarian follicular development and the number of oocytes collected by transvaginal follicular aspiration [8, 9]. Furthermore, passive immunization of mares against inhibin during the follicular phase of the estrous cycle results in a marked increase in plasma concentrations of FSH induced by immunoneutralization of endogenous inhibin, and stimu-

\footnotetext{
* Correspondence to: Miyake, Y-I., Laboratory of Theriogenology, Department of Veterinary Medicine, Faculty of Agriculture, Iwate University, Morioka 020-8550, Japan.
}

lates the rapid growth of a large number of follicles. As a result, multiple ovulations can be induced in mares [16].

This study was undertaken to determine the effects of active immunization of pony mares with a synthetic peptide replica of the amino-terminal sequence of porcine inhibin $\alpha$ subunit on the ovarian function and endocrinology of the estrous cycle.

\section{MATERIALS AND METHODS}

Animals and treatment: Two cyclic, non-pregnant, nonlactating and reproductively healthy pony mares were assigned to this study. The animals weighed 170 and 230 $\mathrm{kg}$, and were 7 and 11 years old, respectively. Before immunization, the two mares were allowed to cycle normally for 3 continuous estrous cycles. Ovarian findings were monitored twice daily by rectal palpation and ultrasonography and these findings were taken as control cycles. The animals were then immunized against a synthetic peptide replica of the amino acid sequence from 1 to 26 (numbering from the $\mathrm{N}$-terminal end) position of the $\alpha$ subunit of porcine inhibin conjugated with rabbit serum albumin (RSA) using Freund's complete adjuvant containing $0.5 \mathrm{mg} / \mathrm{ml}$ heat inactivated tuberculosis (\#55828; ICN Biomedicals Inc., Aurora, Ohio, U.S.A.). The ratio of the weight of porcine inhibin: RSA after conjugation was approximately 1:2 times the amount of porcine inhibin in porcine inhibin-RSA. In the present study, $1.0 \mathrm{mg}$ porcine inhibin in $2.0 \mathrm{~m} l$ saline emulsified in $2.0 \mathrm{~m} l$ Freund's complete adjuvant was injected, and for boosters immunization with $0.5 \mathrm{mg}$ porcine inhibin were given two times with a 39 day interval. 
All injections were given subcutaneously at different sites on both sides of the neck. After the first injection of inhibin for immunization, the animals had 3 estrous periods. The findings during these cycles were compared with the findings in the control cycles and statistically analysed for the number of small $(<1.5 \mathrm{~cm})$, medium $(1.5-3.0 \mathrm{~cm})$ and large $(>3.0 \mathrm{~cm})$ sized follicles and ovulations.

Blood samples: Blood samples were collected by jugular venipuncture during both control cycles and after immunization at 3 day intervals untill 99 days after the first injection of inhibin. Moreover, during the estrous phase and periovulatory period samples were collected daily. The samples were collected in heparinized sterile tubes, centrifuged (3,000 $\mathrm{g}$ for $15 \mathrm{~min})$ within $30 \mathrm{~min}$ after collection and the plasma was stored at $-30^{\circ} \mathrm{C}$ until hormonal assay and inhibin antibody titre assessment.

Assay procedures for inhibin binding activity: Changes in inhibin binding activity in the plasma of mares were determined by measuring the binding of ${ }^{125} \mathrm{I}$-labeled inhibin $(5,000 \mathrm{cpm})$ as reported [6]. Plasma samples obtained at various times after injection of the antiserum were diluted $1: 10$ or $1: 100$ with PBS containing 1\% BSA. An aliquot $(100 \mu l)$ of diluted plasma to which was added $100 \mu l$ PBS was incubated for $24 \mathrm{hr}$ at $32^{\circ} \mathrm{C}$ with ${ }^{125}$ I-labeled bovine 32 $\mathrm{KDa}$ inhibin. Bound tracer was then separated by adding $100 \mu \mathrm{l}$ PBS containing $1 \%$ bovine gamma globulin and 500 $\mu l$ PBS containing $25 \%$ polyethyleneglycol. After centrifugation at $1,700 \mathrm{~g}$ for $30 \mathrm{~min}$, the radioactivity in the precipitate was counted. Inhibin-binding activity was expressed as a percentage of the total counts.

Assay procedures for hormones: Levels of immunoreactive (ir-) inhibin, follicle stimulating hormone (FSH), luteinizing hormone $(\mathrm{LH})$, estradiol-17 $\beta\left(\mathrm{E}_{2}\right)$ and progesterone $(\mathrm{P})$ in peripheral blood were measured by RIA. Plasma concentrations of FSH and LH were measured by using a rabbit against equine FSH (AFP-2062096: provided by NIDDK, NIH, Betheda, MD, U.S.A.) and LH (AFP-240580). Highly purified equine FSH (\#AFP-5022B) and LH (\#AFP-5130A) were used for radioiodination and the reference standard. These materials were kindly provided by Dr. A. F. Parlow (National Hormone and Pituitary Program, Harbor-UCLA Medical Center, CA, U.S.A.). Concentrations of ir-inhibin in plasma were determined by using anti-bovine inhibin serum (TDNH-1) and bovine $32 \mathrm{KDa}$ inhibin for radioiodination and the reference standard [6]. The concentrations of $\mathrm{E}_{2}$ and $\mathrm{P}$ in plasma were determined as described previously $[14,23]$ with antisera to $\mathrm{E}_{2}$ (GDN\#244) and P (GDN\#337). The intra- and inter-assay coefficients of variation were $6.3 \%$ and $7.4 \%$ for ir-inhibin, $6.5 \%$ and $9.2 \%$ for $\mathrm{FSH}, 5.6 \%$ and $8.7 \%$ for $\mathrm{LH}, 8.1 \%$ and $14.2 \%$ for $\mathrm{E}_{2}$ and $5.4 \%$ and $7.2 \%$ for $\mathrm{P}$, respectively.

Observation of ovary: Through the study, mares were examined rectally and ultrasonically in order to monitor the ovarian activity by using a digital liner real time B mode scanner with a $5 \mathrm{MHz}$ probe. The number of small, medium and large sized follicles and ovulations were checked at the time of blood sampling, i.e. at 3 day intervals until 99 days after the first injection.

Statistic analysis: All values are shown as the mean \pm standard error (SEM). Statistical evaluation of data was performed by means of Student's unpaired $t$-test.

\section{RESULTS}

Number of follicles and ovulation before and after immunization: There was a significant increase $(\mathrm{P}<0.05)$ in the number of small, medium and large sized follicles after immunization against inhibin compared with the period before immunization, namely control vs 2nd and 3rd injection, 1 st injection vs 2 nd and 3 rd injection, respectively. On the other hand, there was no change in the ovulation rate, even though the number of large follicles increased significantly after immunization (Table 1).

Inhibin antibody titre before and after immunization against inhibin: As shown in Fig. 1, the anti-inhibin titre increased steadily after the first immunization. There was a significant increase $(\mathrm{P}<0.05)$ between the average titre of the control and the average titre of the 1 st dose, and there was a more significant increase $(\mathrm{P}<0.01)$ between the average titre of the 1st dose and the average titre of the 2 nd and 3rd dose.

Plasma ir-inhibin concentrations before immunization: The plasma ir-inhibin level remained at its lowest values during the early diestrous period and started to increase during the late diestrous and proestrous periods coincident with the development of the dominant follicle(s) before immuni-

Table 1. Number of small, medium and large follicles and number of voulations during the estrous cycle in mares before and after immunization against inhibin

\begin{tabular}{lccccc}
\hline & & \multicolumn{3}{c}{ Follicles } & \\
\cline { 3 - 5 } Group & $\mathrm{n}=$ & $\begin{array}{c}\text { Small } \\
<1.5 \mathrm{~cm}\end{array}$ & $\begin{array}{c}\text { Medium } \\
1.5-3.0 \mathrm{~cm}\end{array}$ & $\begin{array}{c}\text { Large } \\
>3.0 \mathrm{~cm}\end{array}$ & Ovulation \\
\hline Control & 6 & $6.50 \pm 1.43^{\mathrm{a}}$ & $1.83 \pm 0.44^{\mathrm{a}}$ & $1.33 \pm 0.38^{\mathrm{a}}$ & $1.17 \pm 0.24$ \\
Immunized & & & & & \\
1st & 6 & $7.20 \pm 0.01^{\mathrm{ab}}$ & $1.73 \pm 0.81^{\mathrm{ab}}$ & $1.33 \pm 0.09^{\mathrm{ab}}$ & $1.02 \pm 0.09$ \\
2nd & 6 & $9.31 \pm 0.33^{\mathrm{c}}$ & $1.95 \pm 0.76^{\mathrm{c}}$ & $1.81 \pm 0.33^{\mathrm{c}}$ & $1.00 \pm 0.06$ \\
3rd & 6 & $14.12 \pm 0.25^{\mathrm{c}}$ & $3.04 \pm 0.38^{\mathrm{c}}$ & $2.43 \pm 0.65^{\mathrm{c}}$ & $1.12 \pm 0.03$ \\
Total & 6 & $11.75 \pm 4.30^{\mathrm{c}}$ & $2.75 \pm 0.69^{\mathrm{c}}$ & $2.51 \pm 0.25^{\mathrm{c}}$ & $1.15 \pm 0.25$ \\
\hline
\end{tabular}

Values represent the mean \pm SEM of these observations. Significant difference $(<0.05)$; a vs b, a vs c, b vs c. 


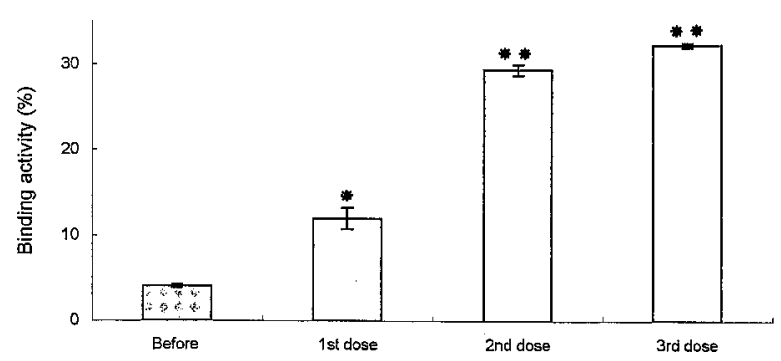

Fig. 1. Ir-inhibin binding antibody activity (\%) before and after immunization against recombinant porcine inhibin. * shows significant difference $(<0.05)$ between before and 1st dose. ** shows significant difference $(<0.01)$ between 1 st dose and 2 nd $\& 3$ rd dose
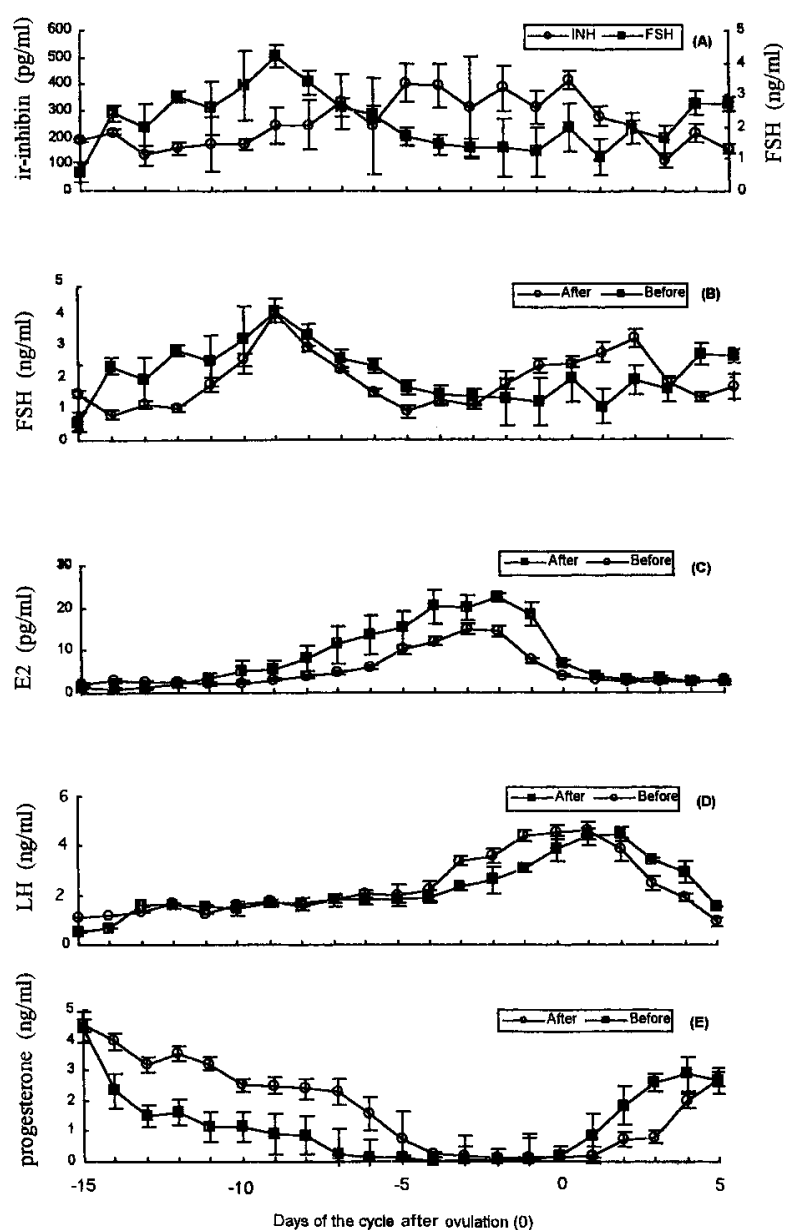

Fig. 2. Changes in plasma ir-inhibin before (A), FSH before (A \& B) and after (B), $\mathrm{E}_{2}$ before and after (C), LH before and after (D) and $\mathrm{P}$ before and after $(\mathrm{E})$ against recombinant inhibin in pony mares.

zation. The peak level of ir-inhibin was noticeable on the day of ovulation (Fig. 2A) before immunization.

Plasma concentrations of FSH, $\mathrm{LH}, \mathrm{E}_{2}$ and $\mathrm{P}$ before and

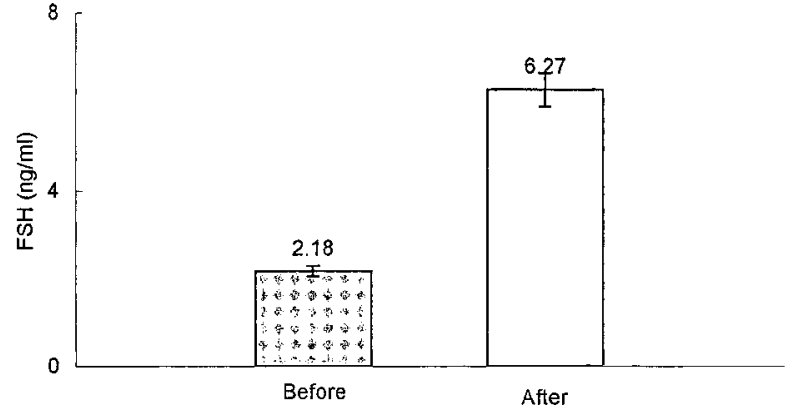

Fig. 3A. Average plasma FSH concentrations during estrous cycle before $(n=6)$ and after $(n=6)$ immunization against recombinant porcine inhibin.

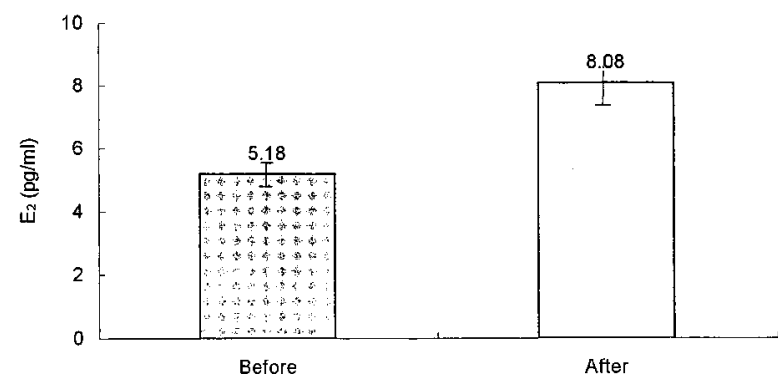

Fig. 3B. Average plasma $\mathrm{E}_{2}$ concentrations during estrous cycle before $(n=6)$ and after $(n=6)$ immunization against recombinant porcine inhibin.

after immunization against inhibin: Circulating FSH levels showed a bimodal pattern throughout the estrous cycle before immunization. The first one occurred during the early estrous period and peaked 9 days before the next ovulation. The second plateau occurred around ovulation and peaked on the day of ovulation (Fig. 2B). After immunization, average plasma FSH concentrations had increased significantly $(\mathrm{P}<0.05)$ compared with those before immunization (6.27 vs $2.18 \mathrm{ng} / \mathrm{ml}$, respectively) (Fig. 3A), but the FSH concentrations remained unchanged after immunization. Plasma concentrations of $\mathrm{E}_{2}$ increased in the late follicular phase both before and after immunization (Fig. 2C) and average concentrations had increased significantly $(\mathrm{P}<0.05)$ after immunization compared with the average concentrations before immunization ( 8.08 vs $5.18 \mathrm{pg} /$ $\mathrm{ml}$, respectively) (Fig. 3B). On the other hand, plasma LH and $\mathrm{P}$ showed changes in their average concentrations before and after immunization against inhibin (Figs. 2D and 2E).

\section{DISCUSSION}

This study demonstrated first, that active immunization against inhibin results in a rise in the circulating inhibin antibody titre, average plasma FSH concentrations and subsequently follicular development. These results clearly 
indicate that inhibin plays an important role in the control of follicular development through the secretion of FSH in the mare. These concepts are in accordance with previous studies on other species such as Japanese monkeys [19], cattle [9] and mares [16]. After immunization, there was a significant increase in the number of small, medium and large sized follicles, but the number of ovulations remained unchanged. These findings suggest that the rising titre against recombinant porcine inhibin is able to bind successfully with endogenous inhibin in the mare's plasma and interfere with its normal inhibitory effect on the secretion of pituitary FSH, since circulating FSH levels increased after immunization. Supporting the present results, many follicles developed and plasma levels of $E_{2}$ increased significantly after the passive immunoneutralization of endogenous inhibin by anti-inhibin serum in mares [16].

It is a well-known fact that the physiological roles of inhibin are as 1) a main inhibitor of FSH secretion, 2) a chemical signal of the number of growing follicles in the ovary and thus 3 ) a key hormone in determining speciesspecific ovulation rates $[4,13,21]$. The significant increase in the number of follicles detected in the present study clearly demonstrates that active immunization will act on follicle development as a factor limiting the number of growing follicles through FSH secretion.

It is reported that in six normally cycling mares, which were immunized 5 times at 3-week intervals with a synthetic bovine inhibin $\alpha$-subunit fragment, the number of ovulated follicles increased significantly compared with the control group [11], whereas, in the present study, the ovulation did not differ significantly in the immunized and control groups. Although the reason for the discrepancy is not clear, immunization against inhibin more than 3 times at relatively short intervals might improve the ovulation rate in the immunized mares. In a previous study, active immunization of thoroughbred and standardbred mares against recombinant inhibin $\alpha$-subunit twice with a 21 day interval increased the ovulation rate in mares [3]. Factors that influence the rate of multiple ovulations are breed, season, reproductive status and genetic predisposition, which might explain the higher incidence of multiple ovulations in Thoroughbred and warm-blooded mares, the intermediate incidence in standardbred mares and the lowest incidence in quarter horses and pony mares [4]. This is may be one of the reasons why mares in this study showed no increase in the ovulation rate after immunization despite the increase in the number of preovulatory follicles.

Whilst the limited number of laboratory animals and observed cycles in this study could not demonstrate the complete range of possible responses to the treatment, these data clearly demonstrated that immunization of pony mares against the porcine inhibin $\alpha$-subunit resulted in the ability of inhibin antibodies to bind the endogenous inhibin molecule and was associated with a significant increase in circulating FSH and the number of follicles. Large follicles could be used for laboratory purposes such as collecting oocytes by transvaginal follicular aspiration in the mare as in cattle [9]. Moreover, the present study supports the previous concept that inhibin exerts an inhibitory effect on FSH and plays a possibly important role in the process of follicular maturation and ovulation.

ACKNOWLEDGEMENTS. We are grateful to Dr. A. F. Parlow and the National Hormone ( Pituitary Program (Harbor-Ucla Medical Center, Torrance, CA, U.S.A.) for providing materials for equine FSH and LH RIAs; and Dr. G. D. Niswender (Animal Reproduction and Biotechnology Laboratory, Colorado State University, Fort Collins, CO, U.S.A.) for providing antisera to estradiol-17( (GDN 244) and progesterone (GDN 337).

\section{REFERENCES}

1. Alexander, S. L. and Irvine, C. H. G. 1993. FSH and LH. pp. 45-46. In: Equine Reproduction (McKinnon, A. O. and Voss, J. L. eds.), Lea and Febiger, Philadelphia.

2. Bergfelt, D. R. and Ginther, O. J. 1986. Follicular populations following inhibition of follicle stimulating hormone with equine follicular fluid during early pregnancy in the mare. Theriogenology 26: 733-747.

3. Bergfelt, D. R., Mann, B. G., Schwartz, N. B. and Ginther, O. J. 1991. Circulating concentrations of immunoreactive inhibin and FSH during the estrous cycle of mares. Equine Vet. Sci. 11: 319-322.

4. Franchimont, P., Henderson, K., Verhoeven, G., Hazee-Hagelstein, M. T., Charlet-Renard, C. H., Demoulin, A., Bourguignon, J. P. and lecomte-Yerna, M. J. 1981. Inhibin : Mechanism of action and secretion. pp. 167-191. In: Intragonadal Regulation of Reproduction (Franchimont, P. and Channing, C. P. eds.), Academic Press, London.

5. Hinrichs, K. 1993. Embryo transfer in the mare: A status report. Anim. Reprod. Sci. 33: 227-240.

6. Kaneko, M., Miyake, Y-I., Kaneda, Y., Watanabe, G. and Taya, K. 1995. Induction of Estrous and promotion of Fertility by Prostaglandin $\mathrm{F}_{2} \alpha$ Administration in mares. J. Equine Sci. 6: 7-14

7. Kaneko, H., Nakanishi, Y., Taya, K., Kishi, H., Watanabe, G., Sasamoto, S. and Hasegawa, Y. 1993. Evidence that inhibin is an important factor in the regulation of FSH secretion during the mid-luteal phase in cows. J. Endocrinol. 136: 35-41.

8. Kaneko, H., Terada, T., Watanabe, G., Taya, K. and Sasamoto, S. 1990. Changes in peripheral levels of immunoreactive inhibin and gonadotrophins in cattle induced to superovulate by porcine follicle-stimulating hormone. Jpn. J. Anim. Reprod. 36: $77-82$.

9. Konishi, M., Aoyagi, Y., Takedomi, T., Itakura, H., Itoh, T., Yazawa, S., Kishi, H., Taya, K., Watanabe, G. and Kanagawa, H. 1996. Effect of active immunization of cattle against follicular development and ultrasound-guided transvaginal follicular aspiration. Theriogenology 46: 33-43.

10. McCue, P. M., Carney, N. J., Hughes, J. P., Rivier, Vale, W. and Lasley, B. L. 1992. Ovulation and embryo recovery rates following immunization of mares against an inhibin alpha-subunit fragment. Theriogenology 38: 823-831.

11. McKinnon, A. O., Brown, R. W., Pashen, R. L., Greenwood, P E. and Vasey, J. R. 1992. Increased ovulation rates in mares after immunization against recombinant bovine inhibin $\alpha$-subunit. Equine Vet. J. 24: 144-146. 
12. Nagamine, N., Nambo, Y., Nagata, S, Nagaoka, S., Tsunoda, N., Taniyama, H., Tanaka, Y., Tohei, A.M., Watanabe, G. and Taya, K. 1998. Inhibin secretion in the mare: Localization of inhibin $\alpha, \beta_{\mathrm{A}}, \beta_{\mathrm{B}}$ subunits in the ovary. Biol. Reprod. 59: 13291398.

13. Nagaoka, K., Nambo, Y., Nagamine, N., Nagata, S., Tanaka, Y., Shinbo, H., Arai, K., Tsunoda, N., Taniyama, H., Watanabe, G., Groome, N. P. and Taya, K. 1999. A selective increase in circulating inhibin and Inhibin Pro- $\alpha \mathrm{C}$ at the time of ovulation in the mare. Am. J. Physiol. 277: 70-75.

14. Nagata, S.M., Kondo, M., Kaneko, H., Araki, K., Nambo, Y., Oikawa, M., Watanabe, G. and Taya, K. 1996. Simple defatting method using a partition method of acetonitrile and n-hexane for radioimmunoassay of low blood levels of estradiol17ß. J. Reprod. Dev. 42: 43-49.

15. Nagata, S., Tsunoda, N., Nagamine, N., Tanaka, Y., Taniyama, Y., Nambo, Y., Watanabe, G. and Taya, K. 1998. Testicular inhibin in the stallion: Cellular source and seasonal changes in its secretion. Biol. Reprod. 59: 62-68.

16. Nambo, Y., Kaneko, H., Nagata, S., Oikawa, M., Yoshihara, T., Nagamine, N., Watanabe, G. and Taya, K. 1998. Effect of passive immunization against inhibin on FSH secretion, folliculogenesis and ovulation rate during the follicular phase of the estrous cycle in mares. Theriogenology 50: 545-557.

17. Nambo, Y., Kaneko, H., Nagata, S., Oikawa, M., Yoshihara, T., Watanabe, G. and Taya, K. 1996a. Inhibin as a regulator of
FSH secretion and folliculogenesis in mare. J. Reprod. Develop. 42: 31-33.

18. Nambo, Y., Nagata, S., Oikawa, M., Yoshihara, T., Tsunoda, N., Kohsaka, T., Taniyama, H., Watanabe, G. and Taya, K. 1996b. High concentrations of immunoreactive inhibin in the plasma of mares and fetal gonads during the second half of pregnancy. Reprod. Fertil. Dev. 8: 1137-1145.

19. Nozaki, M., Watanabe, G., Taya, K., Katakai, Y. and Sasamoto, S. 1991. Circulating inhibin levels during normal menstrual cycle in the Japanese monkey. Jpn. J. Anim. Reprod. 37: 98-103.

20. Squires, E. L., Garcia, R. H., Ginther, O. J., Voss, J. L. and Seidel, G. E. 1986. Comparison of equine pituitary extract and follicle stimulating hormone for superovulating mares. Theriogenology 26: 661-670.

21. Tanaka, Y., Nagamine, N., Nambo, Y., Nagata, S., Nagaoka, K., Tsunoda, N., Taniyama, H., Yoshihara, T., Oikawa, M., Watanabe, G. and Taya, K. 2000. Ovarian secretion of inhibin in mares. J. Reprod. Fertil.(Suppl.) 56: 239-245.

22. Taya, K., Kaneko, H., Takedomi, T., Kishi, H. and Watanabe, G. 1996. Role of inhibin in the regulation of FSH and folliculogenesis in cows. Anim. Reprod. Sci. 42: 563-570.

23. Taya, K., Watanabe, G. and Sasamoto, S. 1985. Radioimmunoassay for progesterone, testosterone and estradiol-17( using 125I-iodohistamine radioligands. Jpn. J. Anim. Reprod. 31: 186-197. 